\title{
Risk factors for asthma exacerbation in patients presenting to an emergency unit of a national referral hospital in Kampala, Uganda.
}

\author{
Richard E Sanya, Bruce J Kirenga, William Worodria, Martin Okot-Nwang
}

Pulmonology unit, Department of Medicine, Makerere College of Health sciences/ Mulago Hospital

\begin{abstract}
Background: Asthma exacerbations are caused by a variety of risk factors. Reducing exposure to these risk factors improves the control of asthma and reduces medication needs. Knowledge of the particular risk factors is essential in formulating controlling and treatment protocols. This study set out to determine the risk factors for asthma exacerbations in patients presenting to the emergency unit of Mulago Hospital.

Methods: An unmatched case-control study involving 43 cases and 43 controls was conducted from November 2011 through February 2012. Asthma patients with exacerbations presenting to Mulago hospital's emergency unit were chosen as cases. The controls were asthma patients recruited from the hospital's outpatient department who had not had an exacerbation in the past 7 days. The study variables were age, sex, level of education, adherence to treatment, exercise, upper respiratory tract infections, household pets, smoking, strong emotions, exposure to in house wood or charcoal burning, weather, use of corticosteroids, beta-blockers and non-steroidal anti-inflammatory drugs. Univariate and multivariate statistical analysis was done using SPSS version 16 to identify independent risk factors for exacerbations.

Results: Lack of corticosteroid use (OR $=22.109 ; 95 \%$ Confidence interval 6.952 to $70.315 ; \mathrm{p}<0.001)$ and presence of upper respiratory tract infections (OR 4.516; CI 1.258-16.213; $\mathrm{p}=0.018$ ) were significantly associated with exacerbations.

Conclusion: Lack of corticosteroid use and upper respiratory tract infections are associated with exacerbations in asthma patients presenting to the Emergency unit of Mulago Hospital
\end{abstract}

Key words: Asthma, asthma exacerbations, risk factors, corticosteroids

DOI:http://dx.doi.org/10.4314/ahs.v14i3.29

\section{Introduction}

Asthma is a worldwide problem with an estimated 300 million people currently affected , 38.9 million from sub-Saharan Africa and a global prevalence ranging from $1 \%$ to $18 \%$ (1). The global prevalence of asthma is continuing to rise with increases in asthma symptom prevalence in Africa (2).

Asthma exacerbations can be associated with a variety of risk factors. Notably asthma exacerbations are associated with exposure to irritants such as cigarette smoke exposure and diesel exhaust fumes $(3,4)$, inhalant allergens such as house dust mites (5), drugs known to worsen asthma (6), poor adherence/non-compliance to therapy (5), extremes in weather ortemperatures (7),

$$
\begin{aligned}
& \text { Corresponding author: } \\
& \text { Sanya Richard } \\
& \text { Pulmonology Unit, } \\
& \text { Department of Medicine Mulago Hospital/ } \\
& \text { Makerere University College of Health Sciences } \\
& \text { P.O. Box } 7072 \text { Kampala, Uganda } \\
& \text { Tel: +256772-945040 } \\
& \text { Email: sanyarich@gmail.com }
\end{aligned}
$$

exercise, respiratory infections (8) and strong emotions (9) to date we are unware of studies investigating risk factors of asthma exacerbations in Mulago Hospital in particular and Uganda in general. A case control study in Canada found symptomatic colds as the most common trigger of asthma exacerbations in the winter and spring, while a transient increase in dust exposure was also identified as a significant trigger (10). However, this is a different environment compared to Uganda in terms of weather and affluence.

Noncompliance to treatment was found as a strong predictor of exacerbations in adult patients in a South African hospital (11).

A study in a university hospital serving developing communities in the Western Cape province, South Africa found the risk factors for severe life threatening asthma to be rural residence, poverty and lack of use of inhaled corticosteroids (12).

The main risk factors for wheeze in urban children in Ethiopia are environmental tobacco smoke, use of kerosene and a longer duration of breastfeeding (13). No study looking at reasons for exacerbations in asthma patients has been done in Mulago Hospital. Knowledge of the particular risk factors precipitating asthma exacerbations in our patients is essential in formulating 
controlling and treatment protocols. The objective of this study was to determine the risk factors for asthma exacerbations in patients presenting to Mulago Hospital.

\section{Methods}

\section{Design and setting:}

This was an unmatched case-control study to investigate the risk factors causing exacerbations in patients with asthma attending the Emergency Unit of Mulago Hospital.

The study was carried out in the Emergency Unit and the Medical Outpatient Department Chest Clinic of Mulago National referral Hospital. The Emergency unit is the portal for all emergencies in the hospital. The medical wing of the emergency unit receives about 80 patients per day. The majority of these are selfreferred patients from the surrounding communities. Asthma exacerbations constitute $2.5 \%$ of emergency visits in Mulago Hospital. Sixty five percent of all asthma visits in Mulago Hospital are due to exacerbations More than $90 \%$ of these patients are treated as outpatients with some being frequently readmitted and having no clear documentation of the risk factors triggering these exacerbations (14).

The chest clinic is a specialist outpatient clinic that provides care to patients with respiratory diseases. About 800 patients are seen in this clinic annually and $16.9 \%$ of them are patients with asthma. The chest clinic operates for one day in a week. The hospital doubles as the teaching hospital for Makerere University College of Health Sciences. (14)

Study eligibility: Patients were included in this study if they were 13 years and older and had asthma. In this study, a patient with asthma was defined as a person with a history of recurrent episodes of wheezing and cough that is often reversible either spontaneously or with treatment and any one of the following: Personal/ family history of asthma and a physician/doctor diagnosis of asthma

The cases were asthma patients who had developed an acute asthma exacerbation. An acute asthma exacerbation was defined in this study as having all four of the following:

1. An emergency room visit because of asthma

2. Forced Expiratory Volume in one second (FEV1) of less than $80 \%$ of the predicted value for age, sex and height.
3. Reduced ratio of $\mathrm{FEV}_{1}$ to Forced Vital Capacity (FEV1/FVC) of less than $70 \%$.

4. Reversibility demonstrated by an increase in FEV of $12 \%$ or $200 \mathrm{mls}$ after the administration of a short acting bronchodilator (salbutamol).

The controls were asthma patients who had had no exacerbations requiring emergency visits during the preceding 7 days but with history of wheezing in the past twelve months.

Patients with any history of pulmonary embolism, active pulmonary TB, chronic obstructive pulmonary disease, known congestive heart failure, known mechanical obstruction (e.g. tumor) were excluded. Prior participation in the study constituted an exclusion criterion. A record of the study participants was kept by the principal investigator and research assistants. Any potential participant's particulars were verified to ensure that they had not participated in the study.

Cases and controls were recruited from the emergency unit and the medical outpatient chest clinic respectively.

\section{Study Variables and definitions:}

The study variables were age, sex, level of formal education, occupation, non-adherence to asthma medication use of corticosteroids, exercise/sport, upper respiratory tract infections, household pets, smoking (active and passive), stoves (exposure to in house wood or charcoal burning), weather and use of drugs known to worsen asthma.

Non-adherence to asthma medication was measured by the 4-item self-report scale developed by Morisky et al (15). Exercise was considered a risk factor if the participant was involved in any formal or informal sports activities including walking distances of at least $1 \mathrm{~km}$. Upper respiratory tract infections (URTI) were seen as a risk factor when at least three of the following five components are marked positive: sore throat, fever, runny/blocked nose, muscle aches and exposure to other people with a cold. The Household pets considered were cats or birds in the house or in the direct work place.

The strong emotions considered were anger, excitement and anxiety. Anger was seen as a risk factor when a participant had any loss of temper during the exposure assessment period. Excitement was seen as a risk factor when a participant was extremely excited or happy about something e.g. sports, finances, or relationships. Anxiety was seen as a risk factor when a participant was anxious for reasons related to death of a relative, work etc. 
Weather was considered as a risk factor for all participants who experienced rainy weather conditions during their exposure assessment period.

The drugs known to worsen asthma are any orally ingested, rectally inserted or injected Non-steroidal anti- inflammatory drug and any Any beta blockercontaining medication.

\section{Sample size calculation:}

The following formulae by James Schlesselman (1974) were used to calculate the sample size.

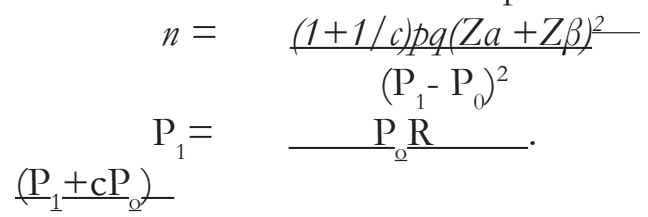

$(1+\mathrm{C})$

Where:

$\mathrm{C}=$ number of controls per case which is 1

$\mathrm{R}$ (Relative Risk) - estimated relative risk (odds ratio)

$=2.18$ Derived from a South African study of asthma

risk factors which found non-adherence to treatment as a risk factor for asthma exacerbation.

$\mathrm{P}_{\mathrm{o}}=$ Expected proportion of controls (asthma patients without exacerbations) $=0.5$ (since we do not know the figures for our setting)

Calculated $\mathrm{P}_{1}=0.69$

Calculated $\mathrm{p}=0.59$

$\mathrm{n}=$ Number of cases i.e. patients with asthma exacerbations

$Z a=1.96$ for $\alpha$ of 0.05 (where $\alpha$ is the significance)

$Z \beta=0.84$ for $\beta$ of 0.2 (where $1-\beta$ is the power)

Substitution of the above values into the formula gives Cases - 38

Assuming 10\% non-responders (NR) will increase the number of cases to 43 and the controls to 43 giving a total sample size of 86 .

\section{Measurements and data Collection:}

Patients with asthma who met the inclusion criteria (both cases and controls) were requested to participate in the study. Their demographic and clinical data were recorded. The procedure and purpose of doing spirometry was explained to the study patients. With the patients seated, spirometry was done using an electronic spirometer (NDD EasyOne, Massachusetts, USA) and the $\mathrm{FEV}_{1}$ and $\mathrm{FEV}_{1} / \mathrm{FVC}$ ratio were measured. Emphasis was made about the essential elements of the test like filling lungs completely, sealing lips around the spirette so that there are no leaks, taking care not to block its opening with teeth or tongue, blowing out as hard and fast as possible and continuing to blow out until the lungs are completely empty. Three acceptable readings were considered.

For the cases (patients in asthma exacerbation), 5 puffs of salbutamol metered dose inhaler were administered using a spacer. Spirometry was repeated after 15 minutes to demonstrate reversibility (increase in $\mathrm{FEV}_{1}$ of $12 \%$ or $200 \mathrm{mls}$ ). Patient care was by the attending physicians. In summary patients received parenteral steroid (intravenous hydrocortisone or oral prednisolone), inhalational bronchodilators by either nebulization or frequent administration of bronchodilators by the metered dose inhaler every 15 minutes and oxygen depending on the severity of the exacerbation. Patients were monitored in the emergency room until stable before transfer to the admitting wards.A structured questionnaire was used as a basis for interviewing the participants. Information obtained about the risk factors included adherence to treatment, upper respiratory tract infections, exercise, smoking, in-house charcoal fires, drugs known to worsen asthma (like beta blockers, NSAIDS), use of corticosteroids, strong emotions and exposure to household pets. Exposure to the risk factors was noted for the previous week (7 days) in both cases and controls.

\section{Data management and analysis:}

Data was entered into Epidata version 3.1 and exported to SPSS version 16.0 for analysis. Continuous data were summarized into means, while categorical variables were summarized into percentages and proportions. A p-value of less than 0.05 was considered significant. We compared baseline characteristics of the cases and controls using Student's $t$ test for when continuous variable and chi-square test when they were proportions. Risk factors for asthma exacerbations were evaluated by logistic regression in univariate and multivariate analyses. Asthma exacerbation was the dependent variable. Following univariate analysis, factors that had association with $\mathrm{p}$-value less 0.20 were entered into a multivariable logistic regression model to assess for independence of association.

\section{Ethics:}

Approval was obtained from the department of Medicine, Mulago Hospital and the Research and Ethics Committee of Makerere University College of Health 
Sciences. Informed consent/assent was obtained from all patients. Confidentiality was ensured throughout the study.

Figure 1: patient flow diagram

2 could not perform spirometry, 2 had no reversibility on spirometry, 1 had normal spirometry and 1 patient declined to participate

\section{Results}

During the study period (November 2011 through February 2012) 49 patients with suspected asthma exacerbation were approached and 43 were recruited.
49 patients with asthma exacerbation

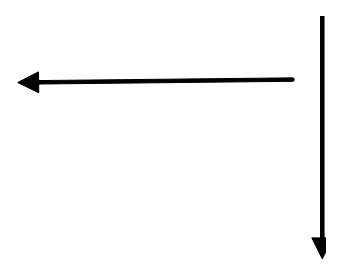

43 Cases

with Asthma

Exacerbation
$1: 1$

43 Controls
Of the 6 who were excluded, 2 could not perform spirometry, 2 had no reversibility on spirometry after administration of inhaled salbutamol, 1 had normal spirometry and 1 patient declined to participate in the study. For each of the 43 cases 1 control was selected in the chest clinic. A total of 43 controls were selected. The demographic characteristics of the study patients are shown in Table1.

Table 1: Demographic characteristics of the study population $(\mathrm{N}=86)$

\begin{tabular}{llll}
\hline Variables & $\begin{array}{l}\text { Cases }(\mathrm{n}=43) \\
\mathrm{n}(\%)\end{array}$ & $\begin{array}{l}\text { Controls(n=43) } \\
\mathrm{n}(\%)\end{array}$ & $\begin{array}{l}\text { Total(n=86) } \\
\mathrm{n}(\%)\end{array}$ \\
\hline Sex & $15(34.9)$ & $19(44.2)$ & $34(39.5)$ \\
Male & $28(65.1)$ & $24(55.8)$ & $52(60.5)$ \\
Female & & & \\
Age & 32.9 & 39.0 & 36.0 \\
Mean age & 14.3 & 18.5 & 16.7 \\
Std deviation & $7(16.3)$ & $12(27.9)$ & $19(22.1)$ \\
Employment & $12(27.9)$ & $9(20.9)$ & $21(24.4)$ \\
Unemployed & $2(4.7)$ & $4(9.3)$ & $6(7.0)$ \\
Self employed & $4(9.3)$ & $5(11.6)$ & $9(10.5)$ \\
Civil servant & $18(41.9)$ & $13(30.2)$ & $31(36.0)$ \\
Peasant & $1(2.3)$ & $2(4.7)$ & $3(3.5)$ \\
Others & $20(46.5)$ & $15(34.9)$ & $35(40.7)$ \\
Education level & $17(39.5)$ & $17(39.5)$ & $34(39.5)$ \\
No formal education & 0 & $3(7.3)$ & $3(3.5)$ \\
Primary education & $5(11.6)$ & $6(14.0)$ & $11(12.8)$ \\
O'level & $16(37.2)$ & $13(30.2)$ & $29(33.7)$ \\
A'level & $16(37.2)$ & $21(48.8)$ & $37(43.0)$ \\
Tertiary & $7(16.3)$ & $5(11.6)$ & $12(14.0)$ \\
Marital status & $4(9.3)$ & $4(9.3)$ & $8(9.3)$ \\
Single & Married & & \\
Separated & Widowed & &
\end{tabular}


Among the 43 cases the mean age was 32.86 years (standard deviation (SD) 14.3) whereas among the 43 controls selected the mean age was 39 (SD 18.48). The majority of the study participants were in the 12-39 year age group (cases $67 \%$, controls $51.2 \%$ )

The clinical characteristics of the study patients are shown in Table 2.

Table2: Clinical characteristics of the study population

\begin{tabular}{lll}
\hline & $\begin{array}{l}\text { Cases (N=43) } \\
\mathbf{n}(\mathbf{\%})\end{array}$ & $\begin{array}{l}\text { Controls (N=43) } \\
\mathbf{n}(\%)\end{array}$ \\
\hline Wheezing after exercise & $39(90.7)$ & $38(88.4)$ \\
Limitation of physical activity by asthma & $37(86)$ & $33(76.7)$ \\
Troublesome cough at night & $39(90.7)$ & $36(87.7)$ \\
$\begin{array}{l}\text { Pre-bronchodilator FEV1 } \\
\geq 80 \% \text { (Normal) }\end{array}$ & & $19(44.2)$ \\
60-79\% Mild Obstruction) & 0 & $11(25.6)$ \\
$40-59 \%$ Mod. Obstruction) & $5(11.6)$ & $7(16.3)$ \\
$<40 \%$ (Severe Obstruction) & $14(32.6)$ & $6(14.0)$ \\
Mean BMI \pm SD & $24(55.8)$ & $22.1 \pm 4.8$ \\
Mean number of attacks in the past 7 days \pm SD & $22.6 \pm 6.0$ & $2.1 \pm 2.8$ \\
Mean number of nights with troublesome cough in & $14.5 \pm 10.9$ & $7.5 \pm 7.2$ \\
the past 4 weeks \pm SD & & \\
Mean Pre-bronchodilator FEV1 \pm SD & $38.5 \pm 16.2$ & $69.3 \pm 23.2$ \\
\hline
\end{tabular}

The cases had five attacks of wheezing in the past seven days while the controls reported two attacks. Of the cases, $39(90.7 \%)$ reported troublesome cough at night over the past one month with a mean of 14.51 nights (SD 10.85) with troublesome cough. Thirty six (87.7\%) controls reported troublesome cough at night over the past one month with a mean of 7.51(SD 7.23) nights of troublesome cough.

\section{Risk factors for asthma exacerbations}

Patients with asthma exacerbations were younger (Mean age 32.86years SD 14.334) than the controls (Mean age 39.0 years SD 18.480) and the difference was statistically significant $(p=0.044)$. Lack of corticosteroid use in the past 7 day was strongly associated with asthma exacerbations (OR 22.101, CI 6.952-70.315, P<0.001). Thirty two of the patients with asthma exacerbation (74.4\%) had not used corticosteroids (oral or inhaled) compared to 5 of the controls $(11.6 \%)$. We also found that presence of upper respiratory tract infections showed a trend towards significance as a risk factor for exacerbations on bivariate analysis (OR 2.1332 CI 0.899-5.052, $\mathrm{P}=0.08$ ) (table 3).

Table 3: Bivariate analysis of the risk factors for asthma exacerbations in the study patients

\begin{tabular}{|c|c|c|c|c|c|}
\hline Variables & $\begin{array}{l}\text { Cases }(\mathrm{N}=43) \\
\mathrm{n}(\%)\end{array}$ & $\begin{array}{l}\text { Controls }(\mathrm{N}=43) \\
\mathrm{n}(\%)\end{array}$ & $\begin{array}{l}\text { Odds } \\
\text { ratio }\end{array}$ & $\mathrm{CI}$ & $\begin{array}{l}\mathrm{P} \\
\text { Value }\end{array}$ \\
\hline Age(Mean \pm SD $)$ & $32.9 \pm 14.3$ & $39.0 \pm 18.48$ & & & 0.044 \\
\hline Education & & & & & 0.354 \\
\hline No formal education & $1(2.3)$ & $2(4.7)$ & & & \\
\hline Primary education & $20(46.5)$ & $15(34.9)$ & 3.286 & $0.025-424.749$ & 0.632 \\
\hline O'level & $17(39.5)$ & $17(39.5)$ & 0.894 & $0.007-116.252$ & 0.964 \\
\hline Alevel & 0 & $3(7.3)$ & 0.000 & 0.000 & 0.999 \\
\hline Tertiary & $5(11.6)$ & $6(14.0)$ & 4.986 & $0.026-958.217$ & 0.549 \\
\hline
\end{tabular}




$\begin{array}{lcccccc}\text { URTI } & \text { yes } & 24(55.8) & 16(37.2) & 2.132 & 0.899-5.053 & 0.086 \\ \text { Living with pets } & \text { No } & 19(44.2) & 27(62.8) & & & \\ & \text { Yes } & 17(39.5) & 15(34.9) & 0.819 & 0.341-1.967 & 0.656 \\ \text { Smoking } & \text { No } & 26(60.5) & 28(65.1) & & & \\ \text { Active Smoking } & \text { Yes } & 4(9.3) & 2(4.7) & 0.476 & 0.082-2.745 & 0.406 \\ & \text { No } & 39(90.7) & 41(95.3) & & & \\ \text { Passive smoking } & \text { Yes } & 17(39.5) & 9(20.9) & 0.405 & 0.156-1.053 & 0.064 \\ \text { Strong emotions } & \text { No } & 26(60.5) & 34(79.1) & & & \\ \text { Anger } & & & & & & \\ & \text { Yes } & 16(37.2) & 11(25.6) & 0.580 & 0.231-1.460 & 0.247 \\ \text { Excitement } & \text { No } & 27(62.8) & 32(74.4) & & & 0.055 \\ \text { Ynxiety } & \text { Yes } & 11(25.6) & 4(9.3) & 0.298 & 0.087-1.027 & \\ & \text { No } & 32(74.4) & 39(90.7) & & & \\ \text { In-house wood burning } & \text { Yes } & 32(74.4) & 33(76.7) & 0.882 & 0.329-2.360 & 0.802 \\ \text { or charcoal stoves } & \text { Yes } & 7(16.3) & 5(11.6) & & & \end{array}$

\begin{tabular}{|c|c|c|c|c|c|c|}
\hline Variables & & Cases(N=43) & Controls $(\mathrm{N}=43)$ & $\begin{array}{l}\text { Odds } \\
\text { ratio }\end{array}$ & CI & $\begin{array}{l}\mathbf{P} \\
\text { Value }\end{array}$ \\
\hline \multirow[t]{2}{*}{ Rainy Weather } & Yes & $29(67.4)$ & $30(69.8)$ & 0.898 & $0.361-2.233$ & 0.816 \\
\hline & No & $14(32.6)$ & $13(69.8)$ & & & \\
\hline \multirow[t]{2}{*}{ Exercise } & Yes & $14(32.6)$ & $10(23.3)$ & 1.593 & $0.615-4.130$ & 0.338 \\
\hline & No & $29(67.4)$ & $33(76.7)$ & & & \\
\hline \multirow[t]{2}{*}{ NSAIDS } & Yes & $5(10.5)$ & $4(9.3)$ & 1.283 & $0.320-5.143$ & 0.725 \\
\hline & No & $38(88.4)$ & $39(90.7)$ & & & \\
\hline Beta-blockers & $\begin{array}{l}\text { Yes } \\
\text { No }\end{array}$ & $\begin{array}{l}0 \\
43(100)\end{array}$ & $\begin{array}{l}2(4.7) \\
41(95.3)\end{array}$ & 0.000 & 0.000 & 0.999 \\
\hline \multirow[t]{2}{*}{ Used corticosteroids } & Yes & $11(25.6)$ & $38(88.4)$ & 0.019 & $0.011-0.144$ & $<0.001$ \\
\hline & No & $32(74.4)$ & $5(11.6)$ & 22.109 & $6.952-70.315$ & $<0.001$ \\
\hline \multirow{2}{*}{$\begin{array}{l}\text { Used inhaled } \\
\text { corticosteroids }\end{array}$} & Yes & $4(9.3)$ & $22(51.2)$ & & & \\
\hline & No & $39(90.7)$ & $21(48.8)$ & 10.214 & $3.107-33.579$ & $<0.001$ \\
\hline \multirow[t]{2}{*}{ Used oral corticosteroids } & Yes & $9(20.9)$ & $32(74.4)$ & & & \\
\hline & No & $32(79.1)$ & $11(25.6)$ & 10.990 & $4.025-30.009$ & $<0.001$ \\
\hline \multirow[t]{2}{*}{ Adherent to medication } & Yes & $17(39.5)$ & $19(44.2)$ & 0.826 & $0.350-1.948$ & 0.662 \\
\hline & No & $26(60.5)$ & $24(55.8)$ & & & \\
\hline
\end{tabular}

As can be seen in table 3, sex, level of education, nonadherence to medication, exercise/sport, household pets, smoking, strong emotions, exposure to in house wood or charcoal burning, rainy weather, non-steroidal anti- inflammatory drugs and beta blockers were not found to be statistically significant risk factors. 
At multivariate level analysis the only factors found to be independently associated with asthma exacerbation were lack of corticosteroid use in the past 7 days $(\mathrm{P}<0.001)$ and upper respiratory tract infections $(\mathrm{P}=0.018)$ (table 4)

Table 4: Factors associated with asthma exacerbation at multivariate analysis

\begin{tabular}{llll} 
Variable & Odds Ratio & CI & P Value \\
& & & \\
\hline Age & 0.755 & $0.523-1.090$ & 0.710 \\
URTI & 4.516 & $1.258-16.213$ & 0.018 \\
Used Corticosteroids & 0.031 & $0.08-0.118$ & $<0.001$ \\
\end{tabular}

\section{Discussion}

This study has established that lack of use of corticosteroids (oral or inhaled) in the past 7 days is associated with asthma exacerbations in Mulago hospital. Inhaled corticosteroids (ICSs) are essential medicines for all but the mildest asthma. Corticosteroids reduce the production of pro-inflammatory cytokines, particularly the Th2 cytokines IL-4, 5 and 13; airway spasmogens like leukotriene LTB4 and LTC4 and thromboxane; and the influx and survival of inflammatory cells specifically eosinophils, lymphocytes, macrophages and mast cells $(16,17)$. The START trial $(18)$, the largest trial of ICSs to date, which established the role of ICSs in reducing exacerbations and improving lung function showed nearly a $50 \%$ reduction in time to first exacerbations in the treatment arm with a significantly reduced (2 vs $0.4 \%$ ) number of severe/life threatening events compared to placebo.

The reasons for failure to use ICSs were not established in this study but could be due to cost, lack of awareness about ICSs among health care providers or patient ignorance. Watson et al in a study to assess the therapeutic aspects of published international asthma management guidelines in developing countries found that many asthma patients in developing countries are not receiving adequate treatment because the required drugs are not available in their area or are prohibitively expensive (19). Regular use of steroid inhalers was correctly prescribed by only $1.8 \%$ surveyed doctors in an Indian study (20). A survey of Nigerian doctors showed that that inhaled corticosteroids were infrequently prescribed (21). A retrospective chart review by Kirenga et al found that only $2.4 \%$ of asthma patients received a prescription of an inhaled corticosteroid from the emergency unit of Mulago Hospital (14). More than half of the controls in this study were on inhaled corticosteroids. This is higher than that found in an earlier study by Kirenga and others where $24.2 \%$ of asthma patients in the chest clinic were on inhaled corticosteroids (14).

Upper respiratory tract infections were significant as a risk factor for exacerbations in this study. This is consistent with a study by Nicholson et al which found that URTI/Viral infections are the cause of an exacerbation in about $65 \%$ of adults with asthma (22). A study in Nigeria of microbial inciters of asthma exacerbation in urban children identified viral agents (RSV, Parainfluenza and influenza viruses) in 53\% of patients and bacterial isolates in only 3.5\% (throat swabs). This emphasizes the importance of viral upper respiratory tract infections in asthma exacerbation (23).

Exercise/sport, household pets, smoking, strong emotions, exposure to in house wood or charcoal burning, rainy weather, NSAIDS and beta blockers were not found to be statistically significant risk factors for asthma exacerbation in this study. This is similar to findings by Geiser and colleagues in a South African hospital (11).

A study by Emerman et al found no relationship between asthma relapse and cigarette smoking or pets in the home (24). None of the patients with asthma exacerbation in this study had received a beta blocker in the preceding week. This is likely due to awareness of the adverse effects.

Although not found to be a risk factor, non-adherence to medication was high in both the cases and controls 
(60.5\% vs. $55.8 \%)$. Gamble and others found poor adherence to be as high as $88 \%$ in patients with severe asthma (25).

Majority of study participants reported limitation of physical activity by asthma, attacks of wheeze in the past 7 days and troublesome cough at night in the past 4 weeks. This shows that most of the asthma patients studied had poorly controlled asthma.

This study had limitations. It may not be generalized beyond the study population, as it involves patients at a single center. The diagnosis of respiratory tract infections was clinical. This being a case control study, recall bias may be a limitation. Only patients with an obstructive picture on spirometry were included as cases. Age and gender were not controlled for in the analysis.

\section{Conclussion}

Lack of corticosteroid use (oral or inhaled) and upper respiratory tract infections are risk factors for exacerbations in asthma patients presenting to the emergency unit of Mulago Hospital. The need to use inhaled corticosteroids as controller therapy for patients with asthma should be emphasized among patients and health care providers

\section{References}

1. Masoli M, Fabian D, Holt S, Beasley R. The global burden of asthma: executive summary of the GINA Dissemination Committee report. Allergy. 2004;59(5):46978. Epub 2004/04/15.

2. Pearce N, Ait-Khaled N, Beasley R, Mallol J, Keil U, Mitchell E, et al. Worldwide trends in the prevalence of asthma symptoms: phase III of the International Study of Asthma and Allergies in Childhood (ISAAC). Thorax. 2007;62(9):758-66. Epub 2007/05/17.

3. Turner MO, Noertjojo K, Vedal S, Bai T, Crump S, Fitzgerald JM. Risk factors for near-fatal asthma. A case-control study in hospitalized patients with asthma. Am J Respir Crit Care Med. 1998;157(6 Pt 1):1804-9. Epub 1998/06/25.

4. Peden DB. Pollutants and asthma: role of air toxics. Environ Health Perspect. 2002;110 Suppl 4:565-8. Epub 2002/08/27.

5. Sporik R, Holgate ST, Platts-Mills TA, Cogswell JJ. Exposure to house-dust mite allergen (Der p I) and the development of asthma in childhood. A prospective study. N Engl J Med. 1990;323(8):502-7. Epub 1990/08/23.
6. Szczeklik A, Stevenson DD. Aspirin-induced asthma: advances in pathogenesis, diagnosis, and management. J Allergy Clin Immunol. 2003;111(5):913-21; quiz 22. Epub 2003/05/14.

7. Abe T, Tokuda Y, Ohde S, Ishimatsu S, Nakamura T, Birrer RB. The relationship of short-term air pollution and weather to ED visits for asthma in Japan. Am J Emerg Med. 2009;27(2):153-9. Epub 2009/04/18.

8. Johnston SL. Viruses and asthma. Allergy. 1998;53(10):922-32. Epub 1998/11/20.

9. von Leupoldt A, Dahme B. Emotions and airway resistance in asthma: study with whole body plethysmography. Psychophysiology. 2005;42(1):92-7. Epub 2005/02/22.

10. Tarlo SM, Broder I, Corey P, Chan-Yeung M, Ferguson A, Becker A, et al. A case-control study of the role of cold symptoms and other historical triggering factors in asthma exacerbations. Can Respir J. 2000;7(1):42-8. Epub 2000/03/04.

11. Geiser MM RP. Risk factors precipitating exacerbations in adult asthma patients presenting at kalafong hospital pretoria. SA Fam Pract. 2008;50(4):67.

12. van der Merwe L, de Klerk A, Kidd M, Bardin PG, van Schalkwyk EM. Case-control study of severe life threatening asthma (SLTA) in a developing community. Thorax. 2006;61(9):756-60. Epub 2006/08/29.

13. Dagoye D, Bekele Z, Woldemichael K, Nida H, Yimam M, Venn AJ, et al. Domestic risk factors for wheeze in urban and rural Ethiopian children. QJM. 2004;97(8):489-98. Epub 2004/07/17.

14. Kirenga J, Okot-Nwang, M. The proportion of asthma and patterns of asthma medications prescriptions among adult patients in the chest, accident and emergency units of a tertiary health care facility in Uganda. African Health Sciences. 2012;12(1):48-53.

15. Morisky DE, Green LW, Levine DM. Concurrent and predictive validity of a self-reported measure of medication adherence. Med Care. 1986;24(1):67-74. Epub 1986/01/01.

16. John M, Lim S, Seybold J, Jose P, Robichaud A, O'Connor $\mathrm{B}$, et al. Inhaled corticosteroids increase interleukin-10 but reduce macrophage inflammatory protein-1alpha, granulocyte-macrophage colony-stimulating factor, and interferon-gamma release from alveolar macrophages in asthma. Am J Respir Crit Care Med. 1998;157(1):256-62. Epub 1998/01/28.

17. Chung KF, Barnes PJ. Cytokines in asthma. Thorax. 1999;54(9):825-57. Epub 1999/08/24.

18. Pauwels RA, Pedersen S, Busse WW, Tan WC, Chen YZ, Ohlsson SV, et al. Early intervention with budes- 
onide in mild persistent asthma: a randomised, double-blind trial. Lancet. 2003;361(9363):1071-6. Epub 2003/04/04.

19. Watson JP, Lewis RA. Is asthma treatment affordable in developing countries? Thorax. 1997;52(7):605-7. Epub 1997/07/01.

20. Shanid S. Knowledge, Attitudes And Practices Of

Primary Care Physicians Of Central Mumbai Suburbs About Childhood Asthma. The Internet Journal of Asthma, Allergy and Immunology. 2007;6(1).

21. Ademola E. Fawibe CCO. Drug prescription pattern for asthma among nigerian doctors in general practice: A cross-sectional survey. Annals of Thoracic Medicine. 2012;7(2):78-83.
22. Nicholson KG, Kent J, Ireland DC. Respiratory viruses and exacerbations of asthma in adults. BMJ. 1993;307(6910):982-6. Epub 1993/10/16.

23. Gbadero DA, Johnson AW, Aderele WI, Olaleye OD. Microbial inciters of acute asthma in urban Nigerian children. Thorax. 1995;50(7):739-45. Epub 1995/07/01.

24. Emerman CL, Cydulka RK. Behavioral and environmental factors associated with acute exacerbation of asthma. Ann Allergy Asthma Immunol. 1998;81(3):23942. Epub 1998/10/06.

25. Gamble J, Stevenson M, McClean E, Heaney LG. The prevalence of nonadherence in difficult asthma. Am J Respir Crit Care Med. 2009;180(9):817-22. Epub 2009/08/01. 